\title{
A CASE OF HYPERTELORISM WITHOUT MENTAL DEFECT.
}

\author{
BY \\ FREDK. M. B. ALLEN, M.D., M.R.C.P.Lond. \\ (Hon. Assist. Physician, Belfast Hospital for Sick Children.) \\ (Medical Registrar, Royal Victoria Hospital, Belfast.)
}

The name " ocular hypertelorism" has been given by Greig to a cranic facial deformity whose main feature is a wide separation of the orbits and their contents. He described two cases (both females) which he had had under observation for a number of years, and also the anatomical findings in the dried skull(2). The only other case in the literature which Greig could find was one described by Hutchison(3) as a case of oxycephaly, but which the photograph showed to be one of hypertelorism. Recently, Muir(4) recorded a case occurring in a female child of 13 months, and he discussed the anatomical findings of Greig's cases and his theory of production. More recently, Cockayne(1) described two cases, one, a female of 7 months, and the other, a boy of 6 years and 9 months. Cockayne came to the conclusion that there was nothing in the family history of these six cases to support Greig's theory as to a hereditary fault. It is noted that of these six cases five were females with gross mental defect. The sixth case (C. F. J. of Cockayne) is a male and it is stated that " mentally he is backward."

A. W., male, aged $4 \frac{1}{2}$ years. The present case shows no signs of mental backwardness. He is the elder of two children and was referred to my Out-Patient Department cn account of bronchitis. His facial peculiarity was noticed; also that the mother had rather widcly separated eyes. The father was seen some time later and it was noticed that he also had widely separated eyes with some flattening of the bridge of the nose. An old "family group" of the father's family was consulted and here the same tendency was obvious. A portion of this is reproduced (Fig. 1) showing the boy's father, uncle, aunt and grandfather.

The pregnancy and birth were normal. Although the parents noticed the boy's peculiar face, they did not pay any attention to it as he developed normally, sat up, walked and talked at the usual times.

Physically there is no defect except that the scrotum is empty and one testicle is in the inguinal canal. The fingers are rather short and tapering. $\mathrm{He}$ is also " pigeon breasted."

There is no mental defect, in fact, he is more than a match for children of his own age. The greatest horizontal circumference of the head is $505 \mathrm{mms}$., the greatest length from glabella to occiput $297 \mathrm{mms}$, and the greatest breadth from the level of the upper border of the pinna to a similar point on the other side $275 \mathrm{mms}$. The length of the head as measured by cephalometer is $176 \mathrm{mms}$. and the breadth $136 \mathrm{mms}$. 


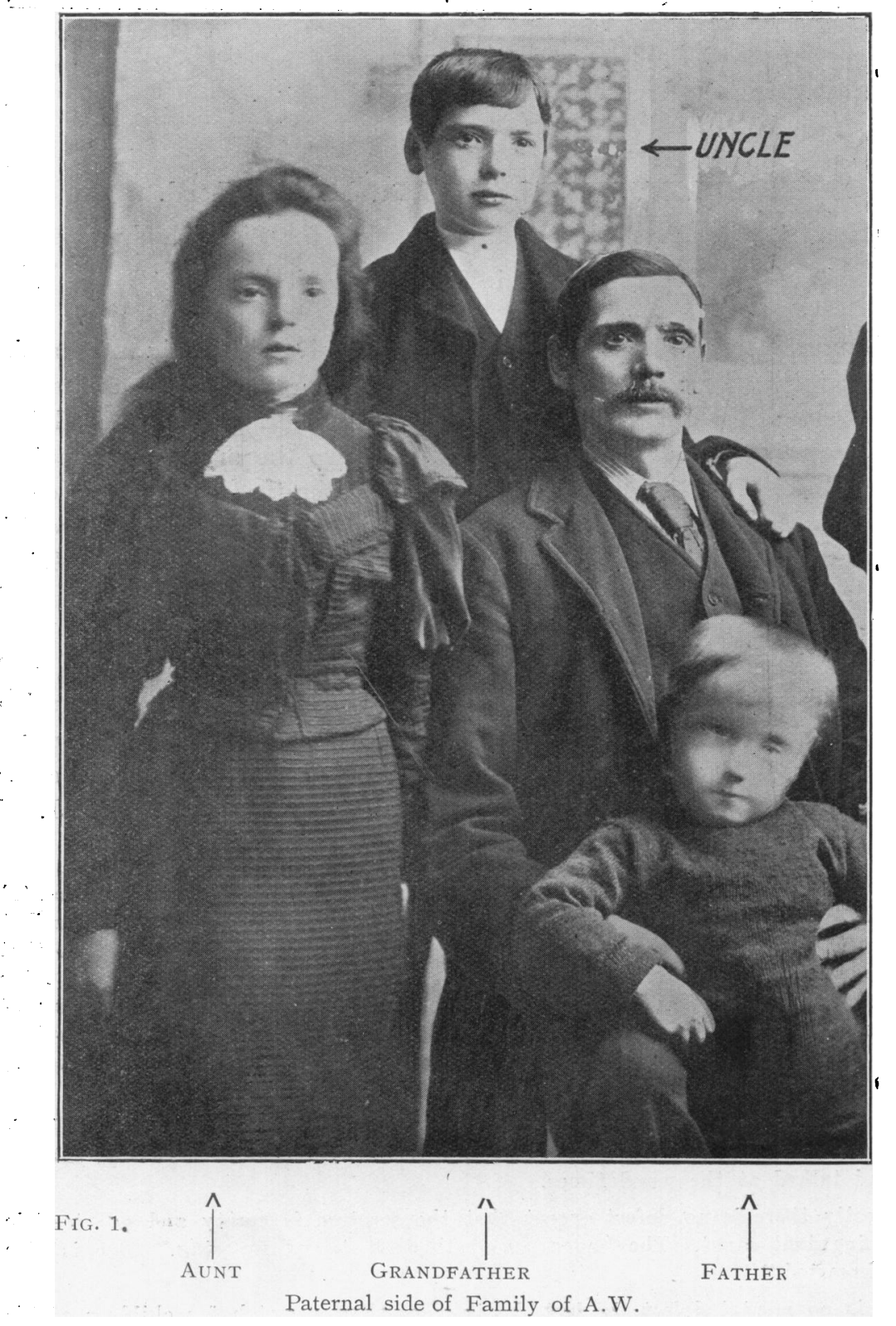




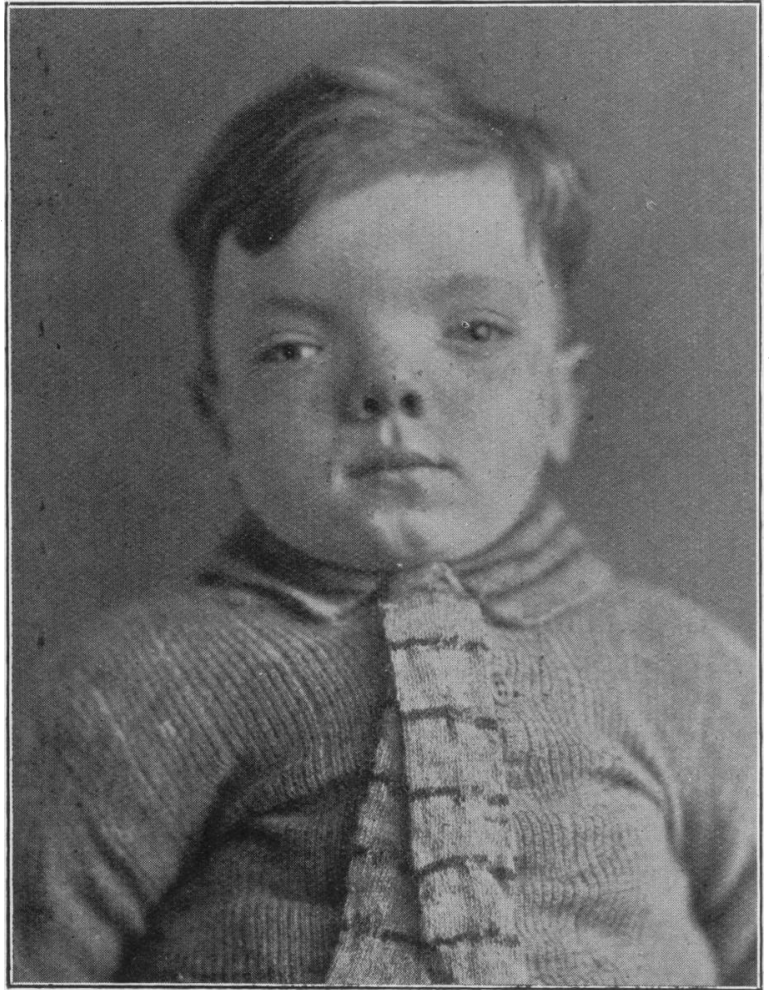

Fig. 2.

A.W. æt. $4 \frac{1}{2}$ years.

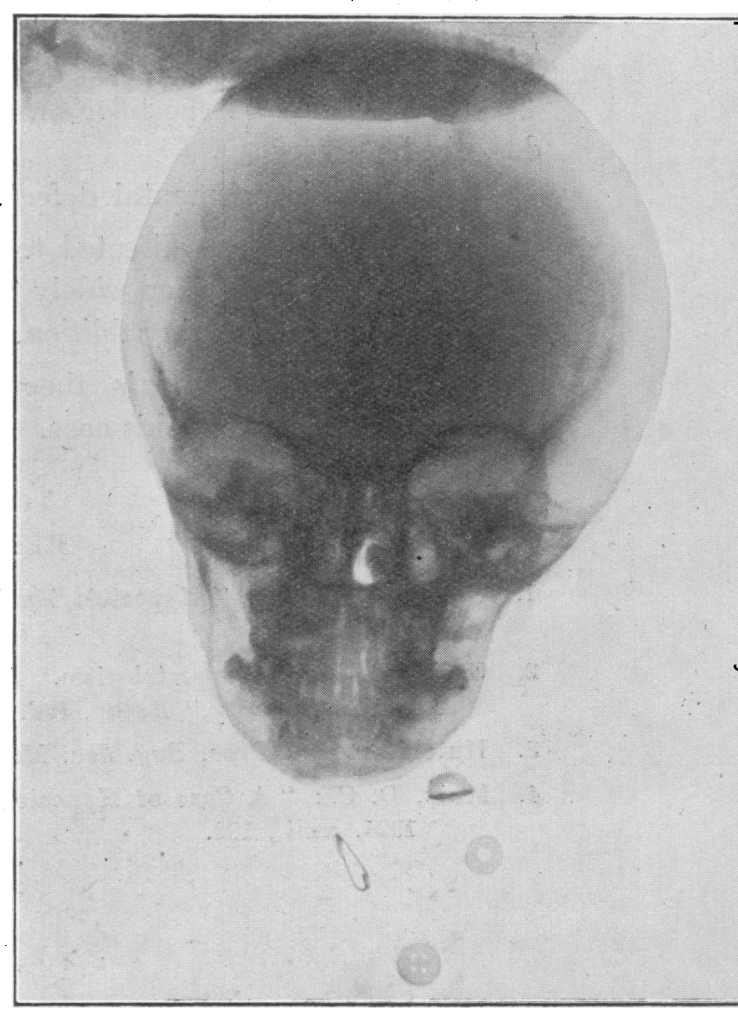

FIG. 3.

Æt. $4 \frac{1}{2}$ years.

The cephalic index is therefore 77 and the head mesaticephalic. The length of the palpebral fissure is $32 \mathrm{mms}$., and the distance between the inner canthi is $41 \mathrm{~mm}$.s. The palate is high and arched. The bridge of the nose is flattened and the nostrils look downward and forward (Fig. 2). Owing to the abnormal relative positions of the eyes, binocular vision is impossible and an alternating strabismus is present. There is a growth of downy fair hair on the back.

The examination of the fundus oculi revealed nothing abnormal. The Wassermann reaction was negative.

'This boy is doubtless one of many similar cases of a mild degree of Greig's hypertelorism, and as he is not mentally defective, as in the cases already reported, these notes are presented.

Mr. Greig, in a private communication, agrees that this is a case of mild degree, and tells me that he knows of a similar case in which there is no mental defect. Added interest is also attached to this case as the parents (especially the father and his family relations) have widely separated eyes. As Mr. Greig states, there is no reason why a maldeveloped sphenoid should not be a familial occurrence and an exaggeration occasionally occur. This case would appear to lend support to ('rreig's view that the condition is the result of a hereditary want of balance in development in certain families. 
Summary.

(1) A case of hypertelorism of mild degree in a boy of $4 \frac{1}{2}$ years is described.

(2) There is no mental defect.

(3) Attention was directed to the parents, and in both it was noticed that the eyes were rather widely separated. In the father there was some flattening of the nose in addition.

(4) Support to Greig's theory of a hereditary want of balance in development is given in this case.

\section{REFERENCES.}

1. Cockayne, E. A. : “Hypertelorism," British Journ. of Children's Diseases, 1925, xxii., 265.

2. Greig, D. M. : “Hypertelorism. A Hitherto Undifferentiated Congenital CranioFacial Deformity," Edin. Med. Journ., 1924, N.S. xxxi., 560.

3. Hutchison, R.: Proc. Roy. Soc. Med., 1909-1910, iii., Sect. Study Dis. Child., 125.

4. Muir, D. C. : “A Case of Hypertelorism," British Journ. of Children's Diseases, 1925, xxii., 102. 